\title{
Assessment of the interaction of land-cover change on shallow landslide occurrence using an automated object-based approach
}

\author{
M. Kamps ${ }^{a}$, A.C. Seijmonsbergen ${ }^{a}$, M. Rutzinger ${ }^{b c}$ and T. Zieher ${ }^{\text {bc }}$ \\ ${ }^{\text {a} U n i v e r s i t y ~ o f ~ A m s t e r d a m ~-~ I n s t i t u t e ~ f o r ~ B i o d i v e r s i t y ~ a n d ~ E c o s y s t e m ~ D y n a m i c s ~(I B E D) ~-~ m a r t i j n t k a m p s @ g m a i l . c o m ~-~}$ \\ a.c.seijmonsbergen@uva.nl \\ ${ }^{\mathrm{b}}$ University Innsbruck - Institute for Geography \\ ${ }^{c}$ Austrian Academy of Sciences - Institute of Interdisciplinary Mountain Research (IGF) - martin.rutzinger@oeaw.ac.at - \\ thomas.zieher@uibk.ac.at
}

\section{KEY WORDS: Data Synergy, OBIA, Landslide, LiDAR, Orthophotos, Land Cover Change}

\begin{abstract}
Land-cover change could considerably lower landslide triggering rainfall thresholds allowing precipitation events with shorter recurrence intervals to initiate shallow landslides. This research focusses on developing an automated, robust and upscalable workflow to quantitatively assess the effect land-cover change has on initiating rainfall induced shallow landslides in the Laternser Valley. Land-cover is classified using four sets of high resolution orthophotos (198x, 2001, 2006, 2009; 0.25 m spatial resolution) by applying an object-based approach with eCognition software. The correlation between land-cover change and landslide occurrence was assessed by analyzing land-cover change trends in the vicinity ( $<25$ meters) of mapped shallow landslides. The obtained classification accuracy ranges from $76 \%$ for $198 \mathrm{x}$ to $88 \%$ for 2009 . The relative area undergoing land-cover change is $18 \%$ in the whole Laternser valley and $34 \%$ in the vicinity of landslides. Overall land-cover change trends indicate a shift from grassland to forest in the whole Laternser valley. However, in the vicinity of landslides the opposite is observed, namely a shift from forest to grassland and grassland to bare soil. Even though a general vegetation reduction is detected in the vicinity of landslides no correlation between LCC and landslide occurrence could be established yet.
\end{abstract}

\section{INTRODUCTION}

Shallow landslides are geomorphological processes occurring in mountainous regions. Shallow landslide susceptibility depends on several factors such as topography, changing land cover and characteristics of subsurface material. Detailed knowledge of fine-scale past and present land cover change (LCC) is a prerequisite for modelling and analysing landslide susceptibility. Classification of high resolution orthophotos - as a transparent and transferable method - is well suited to efficiently and accurately document LCC and to investigate the relation with known landslide-triggering rainfall events. The aims of this research are:

(1). To develop a workflow for automated object-based LCC detection using high resolution orthophotos in the Laternser valley, Austria.

(2). To analyse the correlation between LCC and the temporal occurrence of rainfall triggered shallow landslides.

\section{STUDY AREA}

The Laternser valley is located in the Eastern Alps in Vorarlberg, the westernmost province of Austria. Vorarlberg is a mountainous province characterized by large topographic differences and heterogeneous land-cover. The Laternser valley is situated between $47.23-47.31^{\circ} \mathrm{N}$ and $9.66-9.84^{\circ} \mathrm{E}$ and comprises of an area of $52.1 \mathrm{~km}^{2}$ (Figure 1). Approximately $68 \%$ of the total area has an inclination between 20 and 50 degrees making it generally susceptible to landslides. The geological setting of Vorarlberg was formed by succession of calcareous, dolomitic and pelitic sediments originating from the Mesozoic era (Friebe, 2007). Vorarlberg has a typical Alpine geomorphology characterized by subglacial till, moraine ridges,

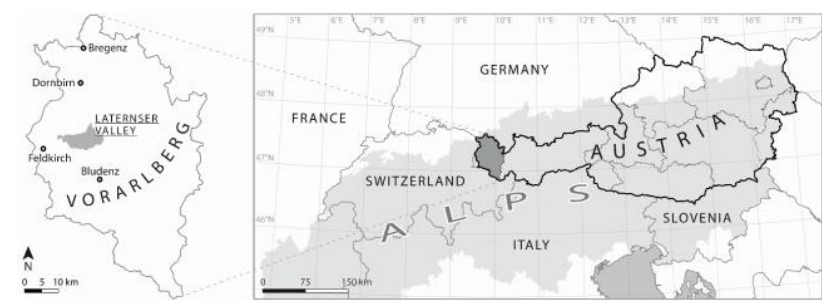

Figure 1. Location of the Laternser Valley in Vorarlberg, western Austria.

ice-marginal landform deposits and cirques (Seijmonsbergen et al., 2014). The Laternser valley is dominated by quaternary, penninic and helvetic nappes (Friebe, 2007) and is drained by a tributary of the Rhine, the river Frutz.

\section{METHODS}

\subsection{Data}

Table 1 shows the meta data of the multi-temporal orthophotos utilized in this research.

\begin{tabular}{|l|l|l|l|l|}
\hline $\begin{array}{l}\text { Orthophoto } \\
\text { series }\end{array}$ & $\begin{array}{l}\text { Photo } \\
\text { scale }\end{array}$ & $\begin{array}{l}\text { GSM } \\
{[\mathrm{m}]}\end{array}$ & $\begin{array}{l}\text { Radiometric } \\
\text { resolution }\end{array}$ & Bands \\
\hline $198 \mathrm{x}$ & $\begin{array}{l}10.000- \\
41.000\end{array}$ & 0.2 & 8 bit & CIR \\
\hline 2001 & $\begin{array}{l}10.000- \\
15.000\end{array}$ & 0.25 & 8 bit & CIR \\
& $10.000-$ & 0.125 & 8 bit & RGB \\
\hline 2006 & 12.000 & & & RGB \\
& $10.000-$ & 0.125 & 8 bit & \\
\hline 2009 & 15.000 & & & \\
\hline
\end{tabular}


Table 1. Meta data of the high resolution orthophoto series. GSD: ground sampling distance, CIR: color infrared imagery, RGB: Red, green, blue; true color imagery. Adopted from Zieher et al., 2016.

A well-documented field- and orthophoto-based inventory of shallow landslides is available for the Laternser Valley in Vorarlberg, developed as part of the project Climate Induced System Status Changes at Slopes and Their Impact on Shallow Landslide Susceptibility (C3S-ISLS). Most of those registered landslides relate to the 1999 and 2005 rainfall events. Figure 2 shows the mapped landslides in three time periods that were analysed in this research. This multi-annual landslide inventory with a 1:400 nominal scale is used as reference dataset for the location of shallow landslides.

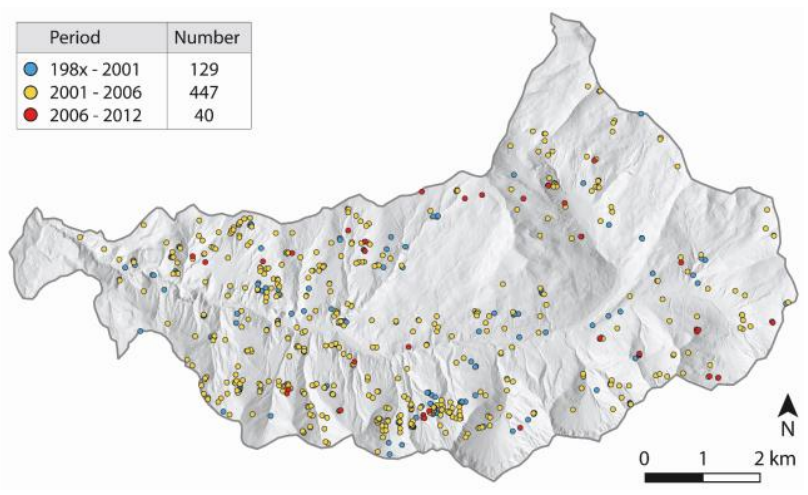

Figure 2. Mapped shallow landslides in the Laternser valley.

\subsection{Workflow}

Figure 3 shows a schematic overview of the general workflow of this research. Four steps are included: pre-processing, analysis, accuracy assessment and the deliverables to work towards the two aims: land-cover change maps and assessing the correlation between LCC and shallow landslide occurrence.

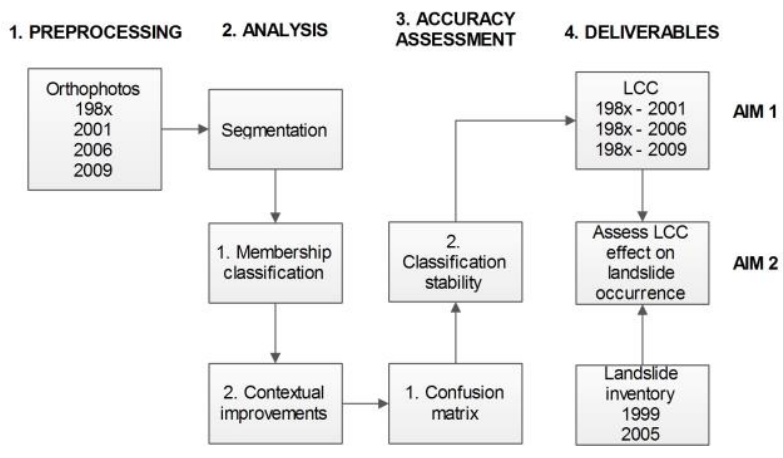

Figure 3. Schematic overview of the workflow.

\subsection{Pre-processing and software}

Pre-processing of the data was performed using ArcGIS 10.3.1 and QGIS 2.4.0. eCognition Developer 9.1.2 software was used to develop the LCC maps. Pre-processing consists of resampling to $0.25 \times 0.25 \mathrm{~m}$ and tiling the orthophotos to tiles of
$2750 \mathrm{~m}$ edge length including an overlap area of $10 \%$ to ensure minimization of object segmentation edge effects.

\subsection{Land Cover Change Analysis}

Our workflow in eCognition Developer for LCC combines segmentation and object-based image analysis of four sets of high resolution orthophotos. Subsequently, post-classification change detection using image differencing was utilized.

Multiscale multiresolution segmentation was utilized to obtain image objects of every land-cover class throughout the whole study area. Scale parameters for multiresolution segmentation were determined with the estimation of scale parameter tool (ESP2) developed by Drăguţ et al. (2014).

The class hierarchy used in this research is: forest, grassland, shadow, bare soil and infrastructure.

To classify the land-cover classes, supervised feature space optimization (FSO) is used to determine the parameter combinations with the highest separation distance (Platt \& Rapoza, 2008). 250 representative (based on expert knowledge) samples of every land-cover class are used by the FSO algorithm on 48 distinct features.

Classification consisted of two steps: (1) stratified membership classification and (2) contextual improvements. The classification workflow was developed and optimized in one tile and subsequently upscaled to the whole of Laternser valley for analysis and validation. A minimum mapping unit of $3.125 \mathrm{~m}^{2}$ (50 pixels) was utilized.

The stratified membership classification was based on the feature thresholds derived from the FSO. The stratified membership classification workflow was designed to be conservative in order to minimize false positives. The contextual improvements were used to classify remaining false negatives.

The contextual improvement rationale was developed to account for landscape homogeneity, variability and overlap in the feature space. The contextual improvements were based on expert interpretation of false positive and false negatives in combination with the original feature space parameters of the objects. Every rule in the workflow only removed a small portion of omission and commission errors.

The land-cover change analysis is performed using postclassification image differencing by automatic comparison of image sub-object hierarchies (Gutierrez et al., 2012; Zhou et al., 2008).

Derivation of LCC trends is utilized for interpretation of LCC in the vicinity $(<25 \mathrm{~m})$ of shallow landslides to quantitatively assess the effect of LCC on rainfall induced landslide occurrence (Begueria, 2006). An automated ArcGIS model is used to calculate the area per land-cover change class using a 25 [m] buffer around the scarpoints derived from the C3S-ISLS project.

\subsection{Accuracy Assessment}

The accuracy assessment consists of two parts: (1) standard confusion matrix, (2) classification stability. 
A stratified sampling scheme was used to obtain 150 samples per period based on the relative occurrence of land-cover classes and the entire range of membership probabilities to obtain a representative sample. Additionally, 150 samples in the vicinity $(<25 \mathrm{~m})$ of landslides were specified to compare the standard overall accuracy with the landslide specific application.

In this study the classification stability was used to differentiate between the segments correctly classified by the initial membership-based classification and the contextual improvements.

\section{RESULTS}

\subsection{Land Cover Change Analysis}

Classification accuracies range from $76 \%$ (198x) to $88 \%$ for the 2009 orthophotos. Kappa statistic falls between $64 \%$ (198x) to $81 \%$ in 2009 . The context based classification ruleset improved $52 \%$ of all accurately classified samples in $198 \mathrm{x}$ and decreases over time to $39 \%$ in 2009 due to better image quality and reduced overlap in the feature space in the more recent years. This research shows the effectiveness of utilizing context to improve classification accuracy after initial membership-based classification in an object-based workflow to deal with overlap in the feature space.

Figure 4 shows the results of the LCC between 198x and 2009 .

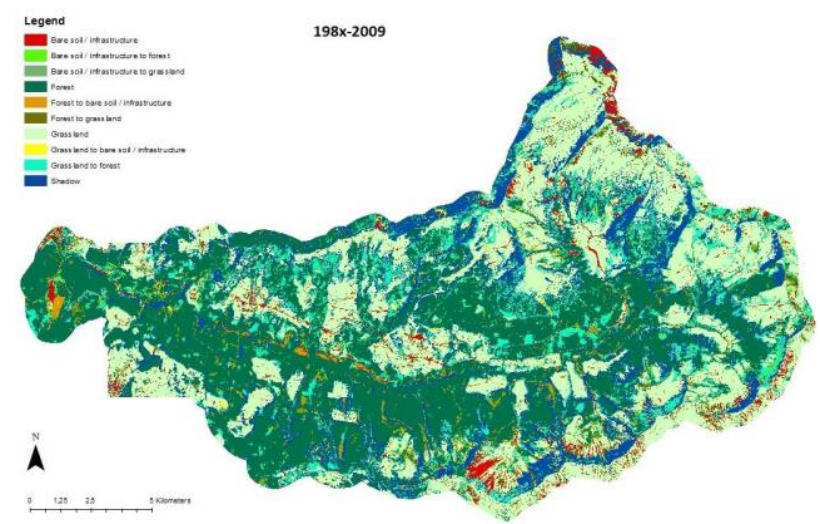

Figure 4. LCC results 198x-2009.

Figure 5 shows the relative area change for every land-cover class from 198x to 2009 in the whole Laternser Valley. A general increase in forest is observed while grassland decreases. Approximately $18 \%$ of the total area undergoes LCC between 198x and 2009. The biggest LCC is the shift from grassland to forest attributing to $10.5 \%$ of the area and $58 \%$ of total LCC. This LCC shift occurs mainly at open areas within the canopy and at the edges of the tree-line.

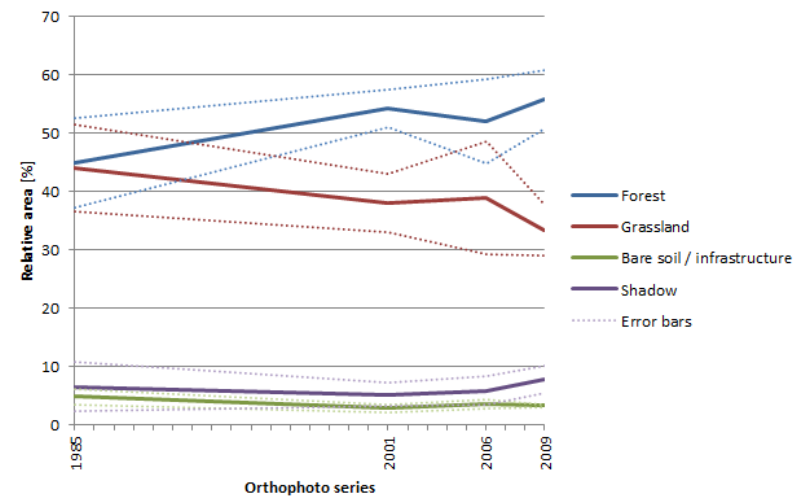

Figure 5. Relative land cover change for the four classes per orthophoto series in the whole Laternser valley. Error bars are derived from the average user/producer accuracy per land-cover class.

\subsection{Change Detection and Landslides}

Land-cover changes that occur in the vicinity $(<25 \mathrm{~m})$ of landslides are shown in figure 6 . Land-cover changes account for $33.9 \%$ (198x-2009) within the $25 \mathrm{~m}$ buffer area. The landcover changes that occur the most are: a shift from grassland to bare soil / infrastructure, and a shift from forest to grassland.

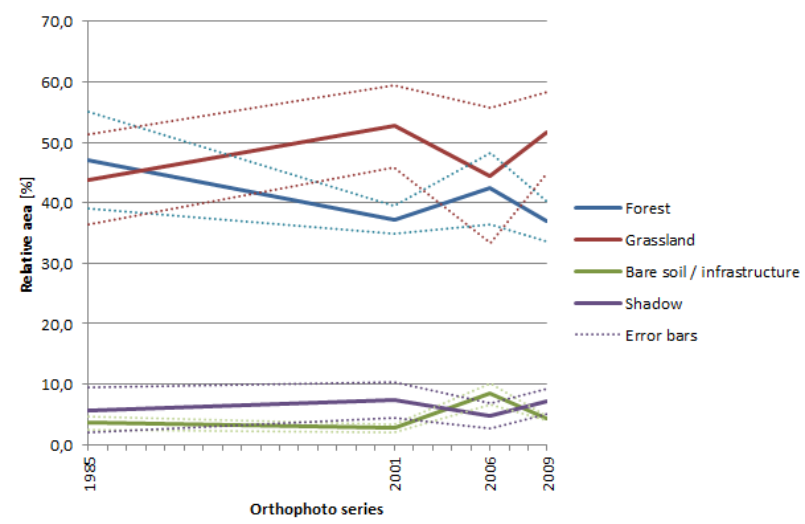

Figure 6. Relative land cover change for the four classes per orthophoto series in the vicinity of landslides. Error bars are derived from the average user/producer accuracy per land-cover class.

\section{CONCLUSION}

In the Laternser valley $18 \%$ of the total area undergoes LCC while in the vicinity of landslides LCC occurs on $34 \%$. Although overall LCC trends indicate a shift from grassland to forest for the Laternser valley, the opposite is observed near shallow landslides. So far, a clear correlation between LCC and landslide occurrence could not be established. The question remains whether the observed land-cover change actually caused the landslides or was the eventual effect of the landslides. Further analysis will incorporate topographic LiDAR data to optimize segmentation and classification and integrate additional explanatory variables for shallow landslide susceptibility such as slope angle, aspect and curvature. Additional ancillary data such as lithology would contribute to strengthening the analysis. 


\section{ACKNOWLEDGEMENTS}

We thank the Federal State of Vorarlberg for providing the necessary data. This work has been conducted within the project C3S-ISLS, which is funded by the Austrian Climate and Energy Fund, 5th ACRP Program.

\section{REFERENCES}

Aguirre-Gutiérrez, J., Seijmonsbergen, A. C., \& Duivenvoorden, J. F. (2012). Optimizing land cover classification accuracy for change detection, a combined pixelbased and object-based approach in a mountainous area in Mexico. Applied Geography, 34, 29-37.

Beguería, S. (2006). Changes in land cover and shallow landslide activity: a case study in the Spanish Pyrenees. Geomorphology, 74(1), 196-206.

Drăguţ, L., Csillik, O., Eisank, C., \& Tiede, D. (2014). Automated parameterisation for multi-scale image segmentation on multiple layers. ISPRS Journal of Photogrammetry and Remote Sensing, 88, 119-127.

Friebe, J. (2007). Geologie der österreichischen bundesländer vorarlberg. Geologische Bundesanstalt, Wien, 154.

Platt, R. V., \& Rapoza, L. (2008). An evaluation of an objectoriented paradigm for land Use/Land cover classification. The Professional Geographer, 60(1), 87-100.

Seijmonsbergen, A. C., De Jong, M. G., de Graaff, L. W., \& Anders, N. S. (2014). Geodiversität von vorarlberg und liechtenstein-geodiversity of vorarlberg and liechtenstein. Haupt Verlag AG.

Zieher, T.; Perzl, F.; Rössel, M.; Rutzinger, M.; Meißl, G.; Markart, G. \& Geitner, C. (2016), 'A multi-annual landslide inventory for the assessment of shallow landslide susceptibility - Two test cases in Vorarlberg, Austria', Geomorphology 259, $40-54$.

Zhou, W., Troy, A., \& Grove, M. (2008). Object-based land cover classification and change analysis in the baltimore metropolitan area using multitemporal high resolution remote sensing data. Sensors, 8(3), 1613-1636. 